This item was submitted to Loughborough's Research Repository by the author.

Items in Figshare are protected by copyright, with all rights reserved, unless otherwise indicated.

\title{
Activity enhancement of tetrahexahedral Pd nanocrystals by bi decoration towards Ethanol electrooxidation in alkaline media
}

PLEASE CITE THE PUBLISHED VERSION

http://dx.doi.org/10.1016/j.electacta.2015.02.177

\section{PUBLISHER}

(C) Elsevier

VERSION

AM (Accepted Manuscript)

\section{PUBLISHER STATEMENT}

This work is made available according to the conditions of the Creative Commons Attribution-NonCommercialNoDerivatives 4.0 International (CC BY-NC-ND 4.0) licence. Full details of this licence are available at: https://creativecommons.org/licenses/by-nc-nd/4.0/

\section{LICENCE}

CC BY-NC-ND 4.0

\section{REPOSITORY RECORD}

Wang, P., Xiao Lin, Bo Yang, Jia-Mei Jin, Christopher Hardacre, Neng-Fe Yu, Shi-Gang Sun, and Wen-Feng Lin. 2016. "Activity Enhancement of Tetrahexahedral Pd Nanocrystals by Bi Decoration Towards Ethanol Electrooxidation in Alkaline Media”. figshare. https://hdl.handle.net/2134/20352. 


\section{Accepted Manuscript}

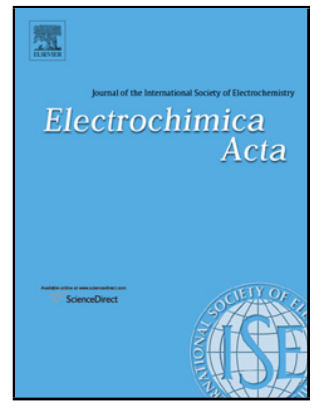

Title: Activity Enhancement of Tetrahexahedral Pd

Nanocrystals by Bi Decoration towards Ethanol

Electrooxidation in Alkaline Media

Author: Ping Wang Xiao Lin Bo Yang Jia-Mei Jin Christopher

Hardacre Neng-Fei Yu Shi-Gang Sun Wen-Feng Lin

PII:

S0013-4686(15)00498-3

DOI:

http://dx.doi.org/doi:10.1016/j.electacta.2015.02.177

Reference:

EA 24456

To appear in:

Electrochimica Acta

Received date:

$16-8-2014$

Revised date:

$19-2-2015$

Accepted date:

20-2-2015

Please cite this article as: Ping Wang, Xiao Lin, Bo Yang, Jia-Mei Jin, Christopher Hardacre, Neng-Fei Yu, Shi-Gang Sun, Wen-Feng Lin, Activity Enhancement of Tetrahexahedral Pd Nanocrystals by Bi Decoration towards Ethanol Electrooxidation in Alkaline Media, Electrochimica Acta http://dx.doi.org/10.1016/j.electacta.2015.02.177

This is a PDF file of an unedited manuscript that has been accepted for publication. As a service to our customers we are providing this early version of the manuscript. The manuscript will undergo copyediting, typesetting, and review of the resulting proof before it is published in its final form. Please note that during the production process errors may be discovered which could affect the content, and all legal disclaimers that apply to the journal pertain. 
Activity Enhancement of Tetrahexahedral Pd Nanocrystals by Bi Decoration towards Ethanol Electrooxidation in Alkaline Media

Ping Wang ${ }^{\mathrm{a}}$, Xiao Lin ${ }^{\mathrm{a}, 1}$, Bo Yang ${ }^{\mathrm{a}}$, Jia-Mei Jin ${ }^{\mathrm{a}}$, Christopher Hardacre ${ }^{\mathrm{a}}$, Neng-Fei Yu ${ }^{\mathrm{b}}$, ShiGang Sun ${ }^{\mathrm{b}}$, Wen-Feng Lin ${ }^{\mathrm{a}^{*}}$ w.lin@qub.ac.uk

${ }^{a}$ Centre for the Theory and Application of Catalysis (CenTACat), School of Chemistry and Chemical Engineering, Queen's University Belfast, Belfast, BT9 5AG, U.K.

${ }^{\mathrm{b}}$ State Key Laboratory of Physical Chemistry of Solid Surfaces, Department of Chemistry, College of Chemistry and Chemical Engineering, Xiamen University, Xiamen 361005, PR China.

*Corresponding author. Tel:+44 289097 4175; fax: +44 2890976524.

${ }^{1}$ Current address: Peterhouse, University of Cambridge, Trumpington Street, Cambridge, CB2 1RD, England, U.K.

\title{
Graphical abstract
}

\section{Highlight}

Tetrahexahedral Pd nanocrystals (THH Pd NCs) without and with Bi decoration were prepared

Activity of bare and Bi decorated THH Pd NCs was studied in alkaline medium at various temperatures

Bi decorated THH Pd NCs exhibited 3 times enhancement in the activity for ethanol oxidation

Activation energy for ethanol oxidation reduced significantly with an optimum Bi-decoration on THH Pd NCs

\begin{abstract}
Tetrahexahedral Pd nanocrystals (THH Pd NCs) were prepared on a glassy carbon electrode using a programmed square-wave potential electrodeposition method, and modified by Bi adatoms with a range of coverages via the cyclic voltammetry method. The reactivity of the catalysts prepared towards ethanol electrooxidation reaction (EOR) was studied in alkaline medium at various temperatures and under other conditions that practical fuel cells operate. Significant activity enhancements were observed for the Bi-modified THH Pd NCs with an optimum Bi coverage $\left(\theta_{\mathrm{Bi}}\right)$ of around 0.68 being obtained. Furthermore, it was found that increasing temperature from $25^{\circ} \mathrm{C}$ to $60^{\circ} \mathrm{C}$ enhances the reactivity significantly. The general kinetics data of EOR on Bi-decorated and bare THH Pd NCs have also been obtained, from
\end{abstract}


the activation energy calculated based on Arrhenius plots, and compared. At the optimum Bi coverage, an enhancement in the activity of almost 3 times was achieved, and the corresponding activation energy was found to be reduced significantly.

Keywords Pd nanocatalyst; Ethanol electrooxidation; Bismuth; Alkaline fuel cell; Electrocatalysis

\section{Introduction}

Direct ethanol fuel cell (DEFC) has been regarded as a promising alternative for the power supply for portable applications and has attracted considerable interests for decades [1-7]. The ethanol fuel can be obtained from fermentation process of biomass and is considered as a green chemical. In addition, it is non-toxic and has high gravimetric and volumetric energy density, as it can transfer 12 electrons per molecule if fully electro-oxidized to $\mathrm{CO}_{2}$ [8-10].

The electrooxidation reaction of ethanol in alkaline media was less popular in contrast with that in acid media. The main constraint is the fact that the hydroxide ions in the alkaline electrolyte may react with the final product, carbon dioxide, to form carbonates. The further precipitation of large solid metal carbonate crystals may alter the $\mathrm{pH}$ of the system, inhibits the transference of the electrolyte and blocks the active sites on the catalyst/electrode [11]. However, since new solid alkaline electrolytes and anion exchange membranes have been developed recently [12-16], increased attention has been focused on alkaline fuel cells. In fact, alkaline electrolytes offer several inherent advantages compared with acidic systems. The enhancement of the kinetics of both fuel oxidation and oxygen reduction reactions has been attributed to the much weaker adsorption of anions in alkaline media. Meanwhile, the less corrosive nature of alkaline electrolyte increases the possibility of using low-cost and Ptfree electrocatalysts. Pd is considered as a promising candidate in this regard, as it is evidenced to be even more active for ethanol electrooxidation than Pt in alkaline media [1721]. Furthermore, $\mathrm{Pd}$ is considerably cheaper than $\mathrm{Pt}$ and is 50 times more abundant on earth [22].

In the fuel cell system, nanoparticle and nanocrystal catalysts are widely used. The catalytic activity of nanocrystals (NCs) is highly dependent on both the composition and the surface 
morphology, largely attributing to electronic effect, surface atomic arrangement and coordination [23]. Furthermore, catalytic performance may depend strongly on the size and shape of metal nanocrystals, and thus a unique and accurate control of these parameters is necessary to maximize nanocatalysts' values [24, 25]. Sun and co-workers recently developed a novel electrochemical method for the preparation of shape-controllable tetrahexahedral (THH) Pd NCs bounded mainly by (730) facets, which is periodically composed of two (210) steps and one (310) facet [26]. It was demonstrated that the THH Pd NCs exhibit 4-6 times higher catalytic activity than commercial Pd black catalyst for ethanol oxidation reaction, which may be attributed to the high density of low coordination atoms located at the steps, kinks and edges of high-index facets. Li et al. [27] reported a new type of hybrid Pd/polyaniline (PANI)/Pd sandwich-structured nanotube array (SNTA), providing fast transport and short diffusion paths for electroactive species and high utilization rate of catalysts. The unique sandwich structure leads to electron delocalization between $\mathrm{Pd} d$ orbitals and PANI $\pi$-conjugated ligands, as well as electron transfer from Pd to PANI [27]. Remita et al. [22] prepared Pd nanowires by electron beam irradiation using hexagonal mesopheres as templates. These nanowires exhibit good electrocatalytic activity and high stability for ethanol electrooxidation [22].

In addition to the morphology effect, the composition of these NCs also plays an important role in the catalytic performance. Recently, Adzic et al. [28-30] developed multifunctional ternary $\mathrm{PtRhSnO}$ and PtIrRh electrocatalysts, which are highly effective in the splitting of C$\mathrm{C}$ bond in ethanol at room temperature and able to oxidize ethanol to $\mathrm{CO}_{2}$ at low overpotentials [28-30]. Teng and co-workers [31] also reported a series of carbon supported Pd-Sn nanocrystals for ethanol electrooxidation where an enhancement in the activity was attributed to the bifunctional effect of the alloy where $\mathrm{Sn}$ or $\mathrm{SnO}_{\mathrm{x}}$ has stronger interactions with hydroxyl group whilst Pd has excellent properties in the adsorption and dissociation of ethanol. The Pd-Sn alloy structure would result in lower reaction energies for the dehydrogenation of ethanol compared to the pure $\mathrm{Pd}$ crystals [31]. A novel $\mathrm{Pt}-\mathrm{PbO}_{\mathrm{x}} \mathrm{NC}$ catalyst has been synthesized by Sun's group via a simple wet chemistry method without using surfactants, organometallic precursors or high temperatures [32]. The as-prepared Pt$\mathrm{PbO}_{\mathrm{x}} \mathrm{NC}$ catalyst exhibited excellent activity for breaking the C-C bond of ethanol, leading to efficient oxidation of ethanol to $\mathrm{CO}_{2}[32]$.

In the present work, we have prepared and modified THH Pd NCs with Bi decoration and studied their reactivity towards ethanol oxidation reaction (EOR) in alkaline media at various 
temperatures and under practical fuel cell operation conditions. It has been demonstrated that Bi-decorated THH Pd NCs with a wide range of Bi coverages exhibit significantly higher catalytic activity than that of bare THH Pd NCs and commercial Pd catalysts. Furthermore, the general kinetics data of EOR on Bi-decorated and bare THH Pd NCs have been obtained and compared, from the activation energy calculated based on Arrhenius plots.

\section{Experimental}

\subsection{Chemicals}

$\mathrm{PdCl}_{2}$ (99.999\%), sulphuric acid (95-98\%), 70\% percholoric acid (99.999\%), bismuth oxide (99.999\%), absolute ethanol ( $\geq 99.9 \%$ ), and sodium hydroxide (semiconductor grade, 99.99\%) were purchased from Sigma-Aldrich. All chemicals were used as received without further purification. Water was purified in a thermoscientific Barnstead water System (18 $\mathrm{M} \Omega \bullet \mathrm{cm}$ resistivity) and was used for the preparation of all aqueous solutions.

\subsection{Electrochemical preparation and characterization}

All electrolyte solutions were deoxygenated using high purity nitrogen unless otherwise stated. A home designed and built, water jacketed variable temperature three-electrode electrochemical cell was used, which includes a piece of gold mesh as the counter electrode, an $\mathrm{Ag} / \mathrm{AgCl}$ (in saturated $\mathrm{KCl}$ ) reference electrode for acidic media or a $\mathrm{Hg} / \mathrm{HgO}$ (in $1 \mathrm{M}$ $\mathrm{NaOH})$ reference electrode for alkaline media, a glassy carbon (GC, $\Phi=7.0 \mathrm{~mm})$ as working electrode. The potentials are converted into the RHE scale in order to facilitate the comparison with other studies in the literatures. The cell was thoroughly cleaned before use: it was initially immersed in a solution of hydrogen peroxide and sulphuric acid for $20 \mathrm{~min}$, then immersed in a boiling water and thoroughly rinsed with hot water. Prior to the electrochemical measurements, the glassy carbon electrode surface was mechanically polished using successively a range of alumina powders of different particle sizes, e.g., 1, 0.3 and $0.05 \mu \mathrm{m}$. It was then washed thoroughly with hot water in an ultrasonic bath for several times.

An Autolab electrochemical work station (Potentiostat, Eco Chemie, Netherlands) together with a waveform generator (HP) were employed for the electro-deposition and electrochemical measurements. Electrochemical data were recorded using Autolab NOVA software. The scan rate of $50 \mathrm{mV} \mathrm{s}^{-1}$ was used in cyclic voltammetry unless otherwise stated. The morphology of THH Pd nanocrystals deposited on the glassy carbon electrode was investigated by Jeol 6500 FEG Scanning Electron Microscope (SEM) operated up to $10 \mathrm{kV}$. 


\subsection{Preparation of THH Pd NCs on the glassy carbon electrode}

THH Pd nanocrystals (NCs) were prepared based on Sun's method reported previously [26], except a longer square-wave potential treatment time of $40 \mathrm{~min}$ (instead of $30 \mathrm{~min}$ ) was used here [26]. As shown in Fig.1, THH Pd NCs were electrodeposited on the glassy carbon (GC) electrode from a solution of $0.2 \mathrm{mM} \mathrm{PdCl}_{2}+0.1 \mathrm{M} \mathrm{HClO}_{4}$ at room temperature. Initially, the GC electrode was subjected to a potential step from $1.514 \mathrm{~V}$ ( $v s \mathrm{RHE}$ ) to $0.214 \mathrm{~V}$ and kept for $20 \mathrm{~ms}$ to produce Pd nuclei. Then, a square-wave potential with the lower potential limit $\left(\mathrm{E}_{\mathrm{L}}\right)$ of $0.614 \mathrm{~V}$ and upper potential limit $\left(\mathrm{E}_{\mathrm{U}}\right)$ of $1.014 \mathrm{~V}$ at $100 \mathrm{~Hz}$ was used for the growth of THH Pd NCs from Pd nuclei.

\subsection{Bi-decoration on THH Pd NCs}

Initially, the THH Pd NCs deposited on the GC electrode was electrochemically cleaned and characterized in $0.1 \mathrm{M} \mathrm{H}_{2} \mathrm{SO}_{4}$ electrolyte solution by continuous potential cycling until the stable cyclic voltammgrams were obtained. The initial potential range used is from 0.09 to $1.36 \mathrm{~V}$ (vs. RHE) for the first 4 cycles with a scan rate at $50 \mathrm{mV} \mathrm{s}^{-1}$. After that, the potential range was set to a narrower window from $0.11 \mathrm{~V}$ to $1.06 \mathrm{~V}$ for another 9 cycles and a stable CV was obtained. In fact, since the Pd high index facets are facile and cannot retain the structure at a too high potential for a prolonged period of time, we found that the upper potential limit of $1.36 \mathrm{~V}$ is high enough for a fast cleaning of the THH Pd NCs in the first 4 cycles. After that, the upper potential limit was set to $1.06 \mathrm{~V}$ for a gentle cleaning. Then, the decoration of bismuth adatoms on the THH Pd NCs was performed by a cyclic voltammetry $(\mathrm{CV})$ in a very dilute $\mathrm{Bi}^{3+}$-containing solution $\left(\sim 10^{-5} \mathrm{M}\right.$ of $\mathrm{Bi}^{3+}$ ions, prepared from $\mathrm{Bi}_{2} \mathrm{O}_{3}$ dissolved in $0.1 \mathrm{M} \mathrm{H}_{2} \mathrm{SO}_{4}$ ) over a potential range of $0.09 \mathrm{~V}$ (vs RHE) to $0.77 \mathrm{~V}$ with a scan rate at $20 \mathrm{mV} \mathrm{s}^{-1}$. The upper potential limit of $0.77 \mathrm{~V}$ was used to prevent surface oxidation. The different Bi coverages were obtained by varying the potential cycling numbers in the $\mathrm{CV}$, following a similar method used by Feliu's group in preparation of Bi adatoms on polyoriented and preferential oriented (111) Pt NCs [33]. After the Bi-decoration, the electrode was rinsed with water and protected with a drop of water, and transferred to another cell containing a solution of $0.1 \mathrm{M} \mathrm{H}_{2} \mathrm{SO}_{4}$ for electrochemical characterization employing $\mathrm{CV}$. The coverage of $\mathrm{Bi}$ was evaluated by the $\mathrm{CV}$ with the potential cycling range between 0.09 and $0.77 \mathrm{~V}$ at a scan rate of $50 \mathrm{mV} \mathrm{s}^{-1}$.

\subsection{Ethanol electrooxidation on bare and Bi-decorated THH Pd NCs}

Electrooxidation of ethanol on the bare and Bi-decorated THH Pd NCs were studied in a solution of $0.1 \mathrm{M}$ ethanol $+0.1 \mathrm{M} \mathrm{NaOH}$ at different temperatures. Both cyclic voltammetry (CV) and chronoampromerty (CA) were employed. The potential sweeping range between - 
0.06 and $1.11 \mathrm{~V}$ (vs. RHE) at a scan rate of $50 \mathrm{mV} \mathrm{s}^{-1}$ was used in the $\mathrm{CV}$, and a fix potential of $0.60 \mathrm{~V}$ (vs. RHE), which is relevant to alkaline ethanol fuel cell, was chosen for the CA. The current density of ethanol electrooxidation was normalized with the electrochemical surface area (ECSA) of bare THH Pd NCs.

\section{Results and discussion}

\subsection{Characterization of bare and Bi-decorated THH Pd NCs}

Fig. 2 shows the representative scanning electron microscopy (SEM) images of the THH Pd NCs deposited on the GC electrode. The insets are two higher magnification SEM images of typical THH Pd NCs as well as the size histogram of THH Pd nanoparticles. It can be seen clearly from these images that all the THH Pd nanocrystals are present as individuals without aggregation, and the THH facets present on the surface of Pd nanocrystals are the same shape as we reported previously [26]. The tetrahexahedral shape with 24 facets is seen as being based upon a cube with a pyramid atop each of the six faces $[23,26]$. The dominant facets of THH Pd NCs were verified to be (730), which are regularly composed of two (210) steps followed by one (310) step [26]. The mean size of individual THH Pd NCs prepared in our 40 min square-wave potential treatment is $c a .50 \mathrm{~nm}$, which is slightly smaller than that $(60 \mathrm{~nm})$ obtained previously in a $30 \mathrm{~min}$ square-wave potential treatment [26], indicating the longer square-wave potential treatment may be beneficial to the fabrication of smaller nanocrystals. The typical cyclic voltammogram of the as-prepared THH Pd NCs in $0.1 \mathrm{M} \mathrm{H}_{2} \mathrm{SO}_{4}$ is represented in Fig.3 (a), which shows an important fingerprint of the THH surface structure. THH Pd was proved to be enclosed by high index (730) facets composing subfacets (210) and (310) [26]. The symmetric cathodic and anodic current peaks between $0.10 \mathrm{~V}$ (vs RHE) and $0.30 \mathrm{~V}$ were attributed to the hydrogen adsorption/desorption processes [26]. Similar to THH Pt NCs, the relative value of the hydrogen desorption current peak around $0.25 \mathrm{~V}$ versus that around $0.15 \mathrm{~V}\left(j_{0.25 \mathrm{~V}} / \mathrm{j}_{0.15 \mathrm{~V}}\right)$ is representative of $\mathrm{CV}$ features of hydrogen desorption on (210) and (310) planes of a Pd single crystal [34]. In addition, the pronounced surface oxygen-containing species adsorption (formation) current peak occurs during the forward potential sweep between $0.72 \mathrm{~V}$ and $0.87 \mathrm{~V}$ [35]. It is noted that this kind of current peak obtained from the THH Pd NCs is significantly sharper than that observed from polycrystalline Pd (on carbon) [35]. The fact that the surface oxygen-containing species (e.g., hydroxyl) being formed at a lower potential than that on polycrystalline flat $\mathrm{Pd}$ surface indicates that THH Pd NCs exhibit high index and low coordinated stepped facets [26]. 
Subsequently, reduction of the oxygen species presents in the backward potential sweep between $0.97 \mathrm{~V}$ and $0.67 \mathrm{~V}$ with the corresponding cathodic peak at around $0.77 \mathrm{~V}$.

In order to further investigate the adsorption of hydroxyl species onto THH Pd NCs, a typical $\mathrm{CV}$ profile of $\mathrm{THH} \mathrm{Pd} \mathrm{NCs}$ in $0.1 \mathrm{M} \mathrm{NaOH}$ alkaline medium is presented in Fig. 3 (b). Compared with the CVs in acidic medium (Fig. 3a), there are several noticeable changes such as a broader but less well-defined hydrogen adsorption/desorption current peak, a significantly narrower double layer region but with higher current, and a less significant but broader current peak associated to surface oxygen-containing (e.g., hydroxyl) species formation/stripping processes. Nevertheless, compared with a polycrystalline $\mathrm{Pd} / \mathrm{C}$ catalyst [31], a more pronounced current peak for surface hydroxyl adsorption/formation was observed for the THH Pd NCs, indicating a stronger interaction between Pd and hydroxyl groups due to the stepped facets being present on the THH Pd NCs. The latter phenomenon is consistent with that observed in the acidic medium (Fig. 3a).

The electrochemical surface area (ECSA) of the THH Pd NCs on GC electrode was evaluated using $\mathrm{CV}$ in $0.1 \mathrm{M} \mathrm{H}_{2} \mathrm{SO}_{4}$ (Fig. 3a), which is similar to that obtained in $0.1 \mathrm{M}$ $\mathrm{HClO}_{4}$ solution, following Sun's approach [26]. The total charge passed during hydrogen adsorption $\left(\mathrm{Q}_{\mathrm{H}}\right)$ /desorption region between 0.12 and $0.37 \mathrm{~V}$, after accounting for the double layer capacity, is used to determine the ECSA, adapting the proven assumption of $212 \mu \mathrm{C}$ $\mathrm{cm}^{-2}$ for Pd surface [26].

For clarity, the evaluation of $\mathrm{Bi}$ coverage carried out by $\mathrm{CV}$ in $0.1 \mathrm{M} \mathrm{H}_{2} \mathrm{SO}_{4}$ between 0.09 and $0.77 \mathrm{~V}$ with a scan rate of $50 \mathrm{mV} \mathrm{s}^{-1}$ is shown in Fig. 3 (c). The evaluation of various Bi coverages $\left(\theta_{B i}\right)$ can be equated with the blockage of hydrogen adsorption. Therefore, $\theta_{B i}$ can be defined as:

$$
\theta_{B i}=1-\theta_{H}=1-\frac{Q_{H}^{B i}}{Q_{H}^{\text {bare }}}(1)
$$

where $Q_{H}^{B i}$ is the charge for hydrogen adsorption on the Bi-decorated THH Pd NCs, while $Q_{H}^{\text {bare }}$ is the charge for hydrogen adsorption on bare THH Pd NCs. The integrations were performed between $0.12 \mathrm{~V}$ and $0.37 \mathrm{~V}$ in hydrogen adsorption region. It can be seen that the presence of Bi results in inhibited hydrogen adsorption and desorption processes on THH Pd NCs (taking $\theta_{B i}=0.68$ as an example). The hydrogen adsorption/desorption peak at around 
$0.20 \mathrm{~V}$ disappears while that at $0.29 \mathrm{~V}$ remains noticeable, indicating $\mathrm{Bi}$ adatoms are preferentially adsorbed on the stepped sites of the THH Pd surface. A similar scenario was reported for Bi decorated $\operatorname{Pt}(775)$ system by Feliu and co-workers [36]. In fact, Feliu et al. found that Bi adatoms on Pt surfaces tend to diffuse and reach a position of minimum energy. The overall rate of $\mathrm{Bi}$ decoration is not only solution diffusion but also surface diffusion controlled, which has to facilitate the decoration of stepped surfaces. Once Bi adatom is deposited on terrace, it moves over the surface until it reaches a stepped site where the energy level for adsorption is lower than that on terrace, $\mathrm{Bi}$ cannot move and is trapped on the stepped site [36]. Anderson also pointed out that the majority of the Bi adatoms were located at stepped and edge sites over the palladium surface while leaving terrace faces unaffected [37].

Figs. 3 (d) and (e) show the CVs of Bi decorated THH Pd NCs in $0.1 \mathrm{M} \mathrm{H}_{2} \mathrm{SO}_{4}$ and $0.1 \mathrm{M}$ $\mathrm{NaOH}$ over a wider potential region to include Bi-adatom oxidation/reduction processes. It can be seen that the oxidation peaks around $0.95 \mathrm{~V} v s$. RHE in both acid and alkaline media represent the oxidation of $\mathrm{Bi}$ adatoms on THH Pd NCs. These results are consistent with previous data of Bi adatoms on Pt electrode by Lin et al. [38] and on THH Pt NCs by Feliu et al. [34]. They performed CO stripping experiments on Bi decorated Pt and THH Pt NCs and found that on $\mathrm{Bi}$ decorated surfaces, the amount of $\mathrm{CO}$ adsorption decreased and, at high $\mathrm{Bi}$ coverages, it became negligible. As CO adsorption on stepped sites is stronger than that on terrace sites, the peak potential shifted to a lower value for $\mathrm{CO}$ stripping once the stepped sites were blocked by $\mathrm{Bi}$ [39]. It is thus expected that $\mathrm{Bi}$ decoration could relieve $\mathrm{CO}$ poisoning effect in ethanol oxidation reaction (EOR) processes after $\mathrm{C}-\mathrm{C}$ bond cleavage, and may lead to high activity for the EOR.

Fig. 4a shows the cyclic voltammograms (CVs) of the ethanol oxidation reaction (EOR) on THH Pd NCs without and at various Bi coverages in $0.1 \mathrm{M}$ ethanol + 0.1 M NaOH. Only four representative $\mathrm{Bi}$ coverages are shown in the figure. All of the current densities are normalized to the electrochemical surface area (ECSA) of the respective bare THH Pd NCs (before Bi decoration). The electrochemical oxidation of ethanol was characterized by the current peaks (reaction kinetics) in the separate forward and reverse potential scans in the CVs. The oxidation current peak in the forward potential scan is more appropriate to be used to evaluate the catalytic activity, as it is associated with the oxidation of ethanol and the adsorbed species produced from ethanol dissociation. The reverse scan may include the surface oxide (formed in the forward scan) reduction current overlapped with ethanol 
oxidation current. The forward peak current density of EOR on bare THH Pd NCs is $2.88 \mathrm{~mA}$ $\mathrm{cm}^{-2}$, which is similar to $2.55 \mathrm{~mA} \mathrm{~cm}$ reported in the literature using the same scan rate of $50 \mathrm{mV} \mathrm{s}^{-1}$ [26], indicating that the THH Pd NCs prepared here are similar to the previously reported in terms of both the shape and the catalytic activity, albeit with a slightly smaller mean size. On the other hand, the peak current density is significantly higher on the Bidecorated THH Pd NCs compared with the bare THH Pd NCs, e.g., the values of 4.78, 8.19 and $3.75 \mathrm{~mA} \mathrm{~cm}^{-2}$ were obtained for the Bi coverages of $0.5,0.68$ and 0.84 , respectively. For the Bi-decorated THH Pd NCs with an optimum Bi-coverage $(\theta=0.68)$, it exhibited almost 3 times higher electro-catalytic activity than bare THH Pd NCs. Compared with Pd black catalyst, the optimum Bi-decorated THH Pd NCs $(\theta=0.68)$ exhibits approximately an 12 times enhancement in the activity towards EOR [26]. The activity enhancement arose from the introduction of Bi to THH Pd NCs could be ascribed to the electronic effect [40], as evidenced from that fact that the presence of Bi results in a broader current peak (see Fig. 4a) as well as an enhanced peak current. Furthermore, Bi modified Pd surface may inhibit the formation of excessive surface oxides such to prevent the deactivation of the catalyst to some extent [41].

In order to further investigate the activity and stability performance of the THH Pd NCs with Bi-decoration, chronoamperometric curves for EOR at $0.60 \mathrm{~V}$ (around the practical fuel cell operation potential) were recorded and shown in Fig. 4b. Prior to the current transients recorded at $0.60 \mathrm{~V}$, the electrodes were initially kept at $0.95 \mathrm{~V}$ for $2 \mathrm{~s}$ to oxidize all the adsorbed intermediates and get the surface cleaned. Subsequently, the electrodes were polarized at $0.10 \mathrm{~V}$ for $3 \mathrm{~s}$ to reduce the oxides formed at $0.95 \mathrm{~V}$. It can be seen from Fig. $4 \mathrm{~b}$ that, compared with the bare THH Pd NCs, the Bi-decorated THH Pd NCs exhibited significantly higher activity/current and also higher stability. The current densities of 0.455 , $0.998,1.470$ and $0.923 \mathrm{~mA} \mathrm{~cm}^{-2}$ were obtained after $100 \mathrm{~s}$ at $0.60 \mathrm{~V}$ for bare and $\mathrm{Bi}$ decorated surfaces at $\mathrm{Bi}$ coverages of $0,0.5,0.68$ and 0.84 , respectively. In agreement with the CV data (in Fig. 4a), compared with the bare THH Pd surface, over 3 times enhancement in the activity/current was observed with the Bi-decorated surface with the optimum $\mathrm{Bi}$ coverage of 0.68 .

Fig. 5 displays the representative CVs of ethanol electrooxidation on THH Pd NCs without and at various Bi coverages $(\theta=0,0.29,0.50,0.56,0.64,0.68,0.79,0.82$ and 0.84$)$ at different temperatures $\left(25,30,40,50\right.$ and $\left.60^{\circ} \mathrm{C}\right)$ in $0.1 \mathrm{M}$ ethanol $+0.1 \mathrm{M} \mathrm{NaOH}$ solution. It is worth to point out that we have checked the Bi coverage again in a second cell containing 
only $0.1 \mathrm{M} \mathrm{NaOH}$ supporting electrolyte, after a set of experiments in the ethanol containing solution where the cyclic voltammograms and the subsequent chronoamperometric curves were recorded, at each temperature, and found no significant change in the Bi coverage. After confirming the Bi coverage, we moved on to the next temperature. In fact, as shown in Fig.3, $\mathrm{Bi}$ (as well as Pd) was oxidized in the forward scan at a higher potential but the oxidized species were reduced again in the reverse scan; the latter can be seen even in the ethanol containing solution as shown in Fig. 4a, where during the reverse scan a small reduction current was observed associating to the reduction process, before the large re-oxidation current appeared in association with ethanol oxidation. The chronoamperometric curves were recorded at $0.60 \mathrm{~V}$ vs RHE where no Bi loss was observed. For all the catalysts studied, a remarkable enhancement in the EOR activity was observed with an increase in temperature from 25 to $60{ }^{\circ} \mathrm{C}$, the onset potential shifted earlier/negatively and current density increased markedly at the elevated temperatures, suggesting that formation of active surface oxidants and the kinetics of EOR were facilitated at higher temperatures [42].

Fig. 6 shows the Arrhenius plots for ethanol electrooxidation reaction (EOR) on the THH Pd NCs without and at various Bi coverages. The data were obtained from Fig. 5 where current density at peak potential on the anodic sweep for EOR at each temperature was used. From these plots, the EOR activation energy was calculated based on Arrhenius equation as below:

$$
\ln j=\ln A-\frac{E_{a}}{R T}
$$

where $j$ is the peak current density, $\mathrm{R}$ the gas constant $\left(8.314 \mathrm{~J} \mathrm{~K}^{-1} \mathrm{~mol}^{-1}\right)$, T the temperature (in $\mathrm{K}$ ) and $E_{a}$ the EOR activation energy (at peak potential on the anodic sweep) [43-45]. It is noted that the $E_{a}$ determination can also be taken at the onset potential or at a constant potential (as the equilibrium potential shows negligible dependence on the temperature), such as $0.500 \mathrm{~V}$, where currents follow Tafel behaviour. The maximum current observed at the peak potential may be considered as the representative of the deepest overall EOR including surface activation whilst the current at a lower (over)potential may be associated with earlier/partial oxidation stage, thus the analysis of $E_{a}$ obtained at both the peak potential and the $0.500 \mathrm{~V}$ is adopted here to facilitate the comparison of $E_{a}$ values with the overall and the earlier EOR processes on the bare and Bi-decorated THH Pd NCs.

The activation energy at the peak potential for the EOR on bare and Bi-decorated THH Pd NCs as a function of Bi coverage is shown in Fig. 7. Fig. 7 also shows the peak current 
densities obtained from CVs at $25^{\circ} \mathrm{C}$. At the Bi coverage of 0.50 , an increased anodic peak current density of $4.78 \mathrm{~mA} \mathrm{~cm}{ }^{-2}$ and decreased activation energy of $34.69 \mathrm{~kJ} \mathrm{~mol}^{-1}$ were obtained, compared to the values of $2.88 \mathrm{~mA} \mathrm{~cm}^{-2}$ and $46.07 \mathrm{~kJ} \mathrm{~mol}^{-1}$ from the bare THH Pd NCs. Further increase in the electro-catalytic activity was achieved by higher Bi coverage on the THH Pd NCs. At an optimum Bi coverage of 0.68 , it exhibited a maximum current density of $8.19 \mathrm{~mA} \mathrm{~cm}^{-2}$, which is almost 3 times higher than that of the bare THH Pd NCs, the corresponding activation energy reduced to a minimum value of $26.48 \mathrm{~kJ} \mathrm{~mol}^{-1}$, which is significantly lower than that $\left(46.07 \mathrm{~kJ} \mathrm{~mol}^{-1}\right)$ obtained from the bare THH Pd NCs. Compared with the apparent activation energies of 30.8 and $36.0 \mathrm{~kJ} \mathrm{~mol}^{-1}$, respectively, for the electrooxidation of ethanol on the PtRu and PtRh catalysts derived based on the same method [44], the value obtained here with the optimum Bi coverage is comparable, with a slightly faster kinetics. This may indicate a similar reaction mechanism including the bifunctional effect of the alloy catalysts where one metal provides sites for ethanol adsorption and the $2^{\text {nd }}$ metal provides sites for water activation.

With even a higher $\mathrm{Bi}$ coverage, e.g., 0.84, the peak current density dropped to a lower value of $3.75 \mathrm{~mA} \mathrm{~cm}^{-2}$ and the corresponding activation energy increased to $37.75 \mathrm{~kJ} / \mathrm{mol}$. Thus apparently a too high Bi coverage may inhibit the overall surface EOR process as there are limited sites available for ethanol adsorption. However, the number of sites will enter the pre-exponential factor rather than the activation energy, the increase in the activation energy may thus come from other effects.

The activation energy obtained at the constant potential of $0.500 \mathrm{~V}$ for the EOR on bare and Bi-decorated THH Pd NCs as a function of Bi coverage is shown in Fig. 8, also shown in the figure is the peak current densities obtained from CVs at $25{ }^{\circ} \mathrm{C}$. As expected, significantly lower activation energies were obtained at this lower potential for bare and Bidecorated THH Pd NCs, compared with the corresponding data obtained at the peak potential (higher potential). This difference may be associated with the fact that the lower activation energy is required to overcome the ethanol partial oxidation at the lower (over)potential; whilst at the peak potential (higher potential) the higher activation energy is required for the deeper oxidation of ethanol and its dissociated intermediates and poison species such as $\mathrm{CO}$ adsorbates. Nevertheless, a similar trend in the variation of the activation energy as a function of $\mathrm{Bi}$ coverage was obtained here at $0.5 \mathrm{~V}$, in comparison to the data obtained at the peak potential. At the optimum Bi coverage around 0.68, the activation energy decreased significantly, afterwards it increased rapidly with further increasing in the Bi coverage, e.g., 
above 0.80 .

We have some initial DFT calculations which show that water activation is the rate determining step on Pd without and at a low Bi coverage; Bi activates water to facilitate EOR and reduce activation energy at the low and optimum Bi coverages. However, at a too high Bi coverage, Bi adatoms may inhibit ethanol adsorption and de-hydrogenation steps which in turn become the rate-determining steps, and such resulting in an increase in the overall activation energy. A more detailed in-sight into the mechanisms will be obtained with a comprehensive in-situ FTIR investigation and DFT atomistic modelling which are on-going and will be reported separately.

\section{Conclusions}

In summary, tetrahexahedral Pd nanocrystals (THH Pd NCs) with a mean particle size of $48 \mathrm{~nm}$ were prepared on a glassy carbon electrode using a programmed square-wave potential electrodeposition method, and modified by Bi adatoms at various coverages via the cyclic voltammetry method. The reactivity of the as prepared nanocatalysts towards ethanol oxidation reaction (EOR) was studied in alkaline medium at various temperatures and under other conditions that practical fuel cells operate. Significant activity enhancements, up to 3 times, were observed for the Bi-modified THH Pd NCs, with an optimum Bi coverage $\left(\theta_{\mathrm{Bi}}\right)$ of around 0.68 being obtained. Increasing temperature from $25^{\circ} \mathrm{C}$ to $60{ }^{\circ} \mathrm{C}$ enhances the reactivity remarkably. The general kinetics data of EOR on Bi-decorated and bare THH Pd NCs were obtained from the activation energy calculated based on Arrhenius plots, and compared. An enhancement of almost 3 times in activity was achieved at the optimum Bi coverage, with corresponding activation energy being reduced significantly.

\section{Acknowledgements}

Financial support from the UK EPSRC (EP/I013229/1) and the State Key Laboratory of Physical Chemistry of Solid Surfaces (Xiamen University) is acknowledged. X.L. thanks QUB for the award of the title of the Visiting Research Associate. W.F.L. thanks N. Tian, Z. Y. Zhou and T. Sheng for very useful discussion. 
[1] C. Lamy, E.M. Belgsir, J.M. Leger, Electrocatalytic oxidation of aliphatic alcohols: Application to the direct alcohol fuel cell (DAFC), J. Appl. Electrochem., 31 (2001) 799-809.

[2] A. Rabis, P. Rodriguez, T.J. Schmidt, Electrocatalysis for Polymer Electrolyte Fuel Cells: Recent Achievements and Future Challenges, ACS Catal., 2 (2012) 864-890.

[3] C. Bianchini, P.K. Shen, Palladium-Based Electrocatalysts for Alcohol Oxidation in Half Cells and in Direct Alcohol Fuel Cells, Chem. Rev., 109 (2009) 4183-4206.

[4] Z. G. Shao, F.Y. Zhu, W.F. Lin, P.A. Christensen, H.M. Zhang, B.L. Yi, Preparation and characterization of new anodes based on Ti mesh for direct methanol fuel cells, J. Electrochem. Soc., 153 (2006) A1575-A1583. .

[5] H. B. Suffredini, G.R. Salazar-Banda, L.A. Avaca, Enhanced ethanol oxidation on PbOxcontaining electrode materials for fuel cell applications, J. Power Sources, 171 (2007) 355362.

[6] S. Q. Song, P. Tsiakaras, Recent progress in direct ethanol proton exchange membrane fuel cells (DE-PEMFCs), Appl. Catal. B-Environ., 63 (2006) 187-193.

[7] K. Taneda, Y. Yamazaki, Study of direct type ethanol fuel cells - Analysis of anode products and effect of acetaldehyde, Electrochim. Acta, 52 (2006) 1627-1631.

[8] W. Zhou, M. Li, L. Zhang, S.H. Chan, Supported PtAu catalysts with different nanostructures for ethanol electrooxidation, Electrochim. Acta, 123 (2014) 233-239.

[9] J. M. Jin, T. Sheng, X. Lin, R. Kavanagh, P. Hamer, P. Hu, C. Hardacre, A. MartinezBonastre, J. Sharman, D. Thompsett, W.F. Lin, Origin of high activity but low $\mathrm{CO}_{2}$ selectivity on binary PtSn catalysts in the direct ethanol fuel cell, Phys. Chem. Chem. Phys., 16 (2014), 9432-9440.

[10] R. Kavanagh, X.M. Cao, W.F. Lin, C. Hardacre, P. Hu, Origin of low $\mathrm{CO}_{2}$ selectivity on platinum in the direct ethanol fuel cells. Angew. Chem. Int. Ed., 51 (2012), 1572-1575.

[11] E. Antolini, E.R. Gonzalez, Alkaline direct alcohol fuel cells, J. Power Sources, 195 (2010) 3431-3450.

[12] C. Coutanceau, L. Demarconnay, C. Lamy, J.M. Leger, Development of electrocatalysts for solid alkaline fuel cell (SAFC), J. Power Sources, 156 (2006) 14-19.

[13] J. R. Varcoe, R.C. T. Slade, An electron-beam-grafted ETFE alkaline anion-exchange membrane in metal-cation-free solid-state alkaline fuel cells, Electrochem. Commun., 8 (2006) 839-843.

[14] K. Matsuoka, Y. Iriyama, T. Abe, M. Matsuoka, Z. Ogumi, Alkaline direct alcohol fuel cells using an anion exchange membrane, J. Power Sources, 150 (2005) 27-31.

[15] J. R. Varcoe, R.C. T. Slade, E. Lam How Yee, An alkaline polymer electrochemical interface: a breakthrough in application of alkaline anion-exchange membranes in fuel cells, Chem. Commun., (2006) 1428-1429. 
[16] C. C. Yang, S.J. Chiu, W.C. Chien, Development of alkaline direct methanol fuel cells based on crosslinked PVA polymer membranes, J. Power Sources, 162 (2006) 21-29.

[17] S. Sen Gupta, J. Datta, Electrode kinetics of ethanol oxidation on novel CuNi alloy supported catalysts synthesized from PTFE suspension, J. Power Sources, 145 (2005) 124132.

[18] C. W. Xu, L.Q. Cheng, P.K. Shen, Y.L. Liu, Methanol and ethanol electrooxidation on $\mathrm{Pt}$ and Pd supported on carbon microspheres in alkaline media, Electrochem. Commun., 9 (2007) 997-1001.

[19] C. W. Xu, Z.Q. Tian, P.K. Shen, S.P. Jiang, Oxide $\left(\mathrm{CeO}_{2}, \mathrm{NiO}, \mathrm{Co}_{3} \mathrm{O}_{4}\right.$ and $\left.\mathrm{Mn}_{3} \mathrm{O}_{4}\right)-$ promoted $\mathrm{Pd} / \mathrm{C}$ electrocatalysts for alcohol electrooxidation in alkaline media, Electrochim. Acta, 53 (2008) 2610-2618.

[20] C. W. Xu, P.K. Shen, Y.L. Liu, Ethanol electrooxidation on Pt/C and Pd/C catalysts promoted with oxide, J. Power Sources, 164 (2007) 527-531.

[21] K. H. Ye, S.A. Zhou, X.C. Zhu, C.W. Xu, P.K. Shen, Stability analysis of oxide $\left(\mathrm{CeO}_{2}\right.$, $\mathrm{NiO}, \mathrm{Co}_{3} \mathrm{O}_{4}$ and $\mathrm{Mn}_{3} \mathrm{O}_{4}$ ) effect on $\mathrm{Pd} / \mathrm{C}$ for methanol oxidation in alkaline medium, Electrochim. Acta, 90 (2013) 108-111.

[22] F. Ksar, G. Surendran, L. Ramos, B. Keita, L. Nadjo, E. Prouzet, P. Beaunier, A. Hagege, F. Audonnet, H. Remita, Palladium Nanowires Synthesized in Hexagonal Mesophases: Application in Ethanol Electrooxidation, Chem. Mat., 21 (2009) 1612-1617.

[23] N. Tian, Z.Y. Zhou, S.G. Sun, Y. Ding, Z.L. Wang, Synthesis of tetrahexahedral platinum nanocrystals with high-index facets and high electro-oxidation activity, Science, 316 (2007) 732-735.

[24] Y. J. Xiong, Y.N. Xia, Shape-controlled synthesis of metal nanostructures: The case of palladium, Adv. Mater., 19 (2007) 3385-3391.

[25] C. Wang, H. Daimon, Y. Lee, J. Kim, S. Sun, Synthesis of monodisperse Pt nanocubes and their enhanced catalysis for oxygen reduction, J. Am. Chem. Soc., 129 (2007) 69746975.

[26] N. Tian, Z.Y. Zhou, N.F. Yu, L.Y. Wang, S.G. Sun, Direct Electrodeposition of Tetrahexahedral Pd Nanocrystals with High-Index Facets and High Catalytic Activity for Ethanol Electrooxidation, J. Am. Chem. Soc., 132 (2010) 7580-7581.

[27] A. L. Wang, H. Xu, J.X. Feng, L.X. Ding, Y.X. Tong, G.R. Li, Design of Pd/PANI/Pd Sandwich-Structured Nanotube Array Catalysts with Special Shape Effects and Synergistic Effects for Ethanol Electrooxidation, J. Am. Chem. Soc., 135 (2013) 10703-10709.

[28] M. Li, D.A. Cullen, K. Sasaki, N.S. Marinkovic, K. More, R.R. Adzic, Ternary Electrocatalysts for Oxidizing Ethanol to Carbon Dioxide: Making Ir Capable of Splitting CC Bond, J. Am. Chem. Soc., 135 (2013) 132-141. 
[29] A. Kowal, M. Li, M. Shao, K. Sasaki, M.B. Vukmirovic, J. Zhang, N.S. Marinkovic, P. Liu, A.I. Frenkel, R.R. Adzic, Ternary $\mathrm{Pt} / \mathrm{Rh} / \mathrm{SnO}_{2}$ electrocatalysts for oxidizing ethanol to $\mathrm{CO}_{2}$, Nat. Mater., 8 (2009) 325-330.

[30] M. Li, A. Kowal, K. Sasaki, N. Marinkovic, D. Su, E. Korach, P. Liu, R.R. Adzic, Ethanol oxidation on the ternary $\mathrm{Pt}-\mathrm{Rh}-\mathrm{SnO}_{2} / \mathrm{C}$ electrocatalysts with varied $\mathrm{Pt}: \mathrm{Rh}: \mathrm{Sn}$ ratios, Electrochim. Acta, 55 (2010) 4331-4338.

[31] W. X. Du, K.E. Mackenzie, D.F. Milano, N.A. Deskins, D. Su, X.W. Teng, PalladiumTin Alloyed Catalysts for the Ethanol Oxidation Reaction in an Alkaline Medium, ACS Catal., 2 (2012) 287-297.

[32] W. H. Yang, H.H. Wang, D.H. Chen, Z.Y. Zhou, S.G. Sun, Facile synthesis of a platinum-lead oxide nanocomposite catalyst with high activity and durability for ethanol electrooxidation, Phys. Chem. Chem. Phys., 14 (2012) 16424-16432.

[33] A. Lopez-Cudero, F.J. Vidal-Iglesias, J. Solla-Gullon, E. Herrero, A. Aldaz, J.M. Feliu, Formic acid electrooxidation on Bi-modified polyoriented and preferential (111) Pt nanoparticles, Phys. Chem. Chem. Phys., 11 (2009) 416-424.

[34] Q. S. Chen, Z.Y. Zhou, F.J. Vidal-Iglesias, J. Solla-Gullon, J.M. Feliu, S.G. Sun, Significantly Enhancing Catalytic Activity of Tetrahexahedral Pt Nanocrystals by Bi Adatom Decoration, J. Am. Chem. Soc., 133 (2011) 12930-12933.

[35] H. Liu, A. Manthiram, Controlled synthesis and characterization of carbon-supported $\mathrm{Pd}_{4} \mathrm{Co}$ nanoalloy electrocatalysts for oxygen reduction reaction in fuel cells, Energy Environ. Sci., 2 (2009) 124-132.

[36] E. Herrero, V. Climent, J.M. Feliu, On the different adsorption behavior of bismuth, sulfur, selenium and tellurium on a Pt(775) stepped surface, Electrochem. Commun., 2 (2000) 636-640.

[37] J. A. Anderson, J. Mellor, R.P. K. Wells, Pd catalysed hexyne hydrogenation modified by $\mathrm{Bi}$ and by Pb, J. Catal., 261 (2009) 208-216.

[38] W. F. Lin, S.G. Sun, Z.W. Tian, Investigations of Coadsorption of Carbon-Monoxide with S or Bi Adatoms at a Platinum-Electrode by in-Situ Ftir Spectroscopy and QuantumChemistry Analysis, Journal of Electroanalytical Chemistry, 364 (1994) 1-7.

[39] Q. S. Chen, A. Berna, V. Climent, S.G. Sun, J.M. Feliu, Specific reactivity of step sites towards $\mathrm{CO}$ adsorption and oxidation on platinum single crystals vicinal to $\mathrm{Pt}(111)$, Phys. Chem. Chem. Phys., 12 (2010) 11407-11416.

[40] C. T. Wu, K.M. K. Yu, F.L. Liao, N. Young, P. Nellist, A. Dent, A. Kroner, S.C.E. Tsang, A non-syn-gas catalytic route to methanol production, Nat. Commun., 3 (2012) 8.

[41] A. Zalineeva, A. Serov, M. Padilla, U. Martinez, K. Artyushkova, S. Baranton, C. Coutanceau, P.B. Atanassov, Self-Supported $\mathrm{Pd}_{\mathrm{x}} \mathrm{Bi}$ Catalysts for the Electrooxidation of Glycerol in Alkaline Media, J. Am. Chem. Soc., 136 (2014) 3937-3945. 
[42] S. S. Mahapatra, A. Dutta, J. Datta, Temperature effect on the electrode kinetics of ethanol oxidation on Pd modified Pt electrodes and the estimation of intermediates formed in alkali medium, Electrochim. Acta, 55 (2010) 9097-9104.

[43] J. L. Cohen, D.J. Volpe, H.D. Abruna, Electrochemical determination of activation energies for methanol oxidation on polycrystalline platinum in acidic and alkaline electrolytes, Phys. Chem. Chem. Phys., 9 (2007) 49-77.

[44] B. Pierozynski, Ethanol Electrooxidation on PtRh and PtRu Catalytic Surfaces in $0.1 \mathrm{M}$ $\mathrm{NaOH}$, Int. J. Electrochem. Sci., 7 (2012) 6406-6416.

[45] R. W. Tsang, D.C. Johnson, G.R. Luecke, The apparent activation-energy for the electrochemical oxidation of $\mathrm{HCOOH}$ at a platinum-electrode chemically modified by $\mathrm{Bi}$ adatoms in $0.5 \mathrm{~m} \mathrm{H}_{2} \mathrm{SO}_{4}$, J. Electrochem. Soc., 131 (1984) 2369-2373.

Figure captions

Fig. 1 Schematic illustration of the programmed electrodeposition approach for the preparation of tetrahexahedral (THH) Pd nanocrystals (NCs) on the glassy carbon (GC) electrode. The potentials are given in the RHE scale.

Fig. 2 SEM image shows THH Pd NCs deposited on the GC electrode. The insets are two high-magnification images of the typical THH Pd NCs, and the size histogram of the THH Pd NCs.

Fig.3 Cyclic voltammograms (CVs) of (a and b) THH Pd NCs in (a) $0.1 \mathrm{M} \mathrm{H}_{2} \mathrm{SO}_{4}$ and (b) 0.1 $\mathrm{M} \mathrm{NaOH}$, and (c) THH Pd NCs and Bi decorated THH Pd NCs $\left(\theta_{\mathrm{Bi}}=0.68\right)$ in $0.1 \mathrm{M} \mathrm{H}_{2} \mathrm{SO}_{4}$. Also shown are the CVs of the Bi decorated THH Pd NCs in (d) $0.1 \mathrm{M} \mathrm{H}_{2} \mathrm{SO}_{4}$ and (e) $0.1 \mathrm{M}$ $\mathrm{NaOH}$ over a wider potential range to include $\mathrm{Bi}$ oxidation and reduction processes.

Fig.4 (a) Cyclic voltammograms (CVs) showing the activity of the THH Pd NCs without and at various Bi coverages (indicated in the figure) towards ethanol oxidation reaction (EOR) in $0.1 \mathrm{M}$ ethanol + $0.1 \mathrm{M} \mathrm{NaOH}$ solution, scan rate: $50 \mathrm{mV} \mathrm{s}^{-1}$; (b) current transients recorded at $0.600 \mathrm{~V} v s$. RHE, for EOR on Bi-decorated THH Pd NCs without and at various Bi coverages.

Fig. 5 Cyclic voltammograms (CVs) showing the activity of THH Pd NCs without (a) and at various Bi coverages (b-h), toward ethanol electrooxidation at different temperatures in $0.1 \mathrm{M}$ ethanol + 0.1 M NaOH solution. (a): THH Pd; (b-f) Bi-decorated THH Pd: (b) $\theta=0.50$, (c) $\theta$ $=0.68$, (d) $\theta=0.79$, (e) $\theta=0.82$, (f) $\theta=0.84$. Scan rate: $50 \mathrm{mV} \mathrm{s}^{-1}$. Only representative $\mathrm{Bi}$ coverages are shown for the clarity.

Fig. 6 Arrhenius plots of the ethanol oxidation reaction (EOR) on the THH Pd NCs without (a) and at various Bi coverages (b-f), the data were obtained from current densities at peak potential on the anodic sweep for EOR at different temperatures in $0.1 \mathrm{M}$ ethanol $+0.1 \mathrm{M}$ $\mathrm{NaOH}$ solution; (a) bare THH Pd, (b-f) Bi-decorated THH Pd with Bi coverages of (b) $\theta=$ 0.29 , (c) $\theta=0.50$, (d) $\theta=0.68$ (e) $\theta=0.79$, (f) $\theta=0.84$. Only representative Bi coverages are shown for the clarity.

Fig.7 Plots of the peak current density (red line - $\mathbf{\Delta}-$ ) and activation energy (blue line - $\bullet-$ ) obtained at the peak potentials for ethanol oxidation reaction (EOR) on bare and Bi-decorated THH Pd NCs as a function of Bi-coverage. Activation energies were calculated from the Arrhenius plots in Fig. 6, whilst peak current densities were referred to CVs of EOR at $25{ }^{\circ} \mathrm{C}$, for the clarity. 
Fig. 8 Plots of the peak current density from the CVs of ethanol oxidation reaction (EOR) at $25{ }^{\circ} \mathrm{C}$ (red line - $\boldsymbol{\Delta}^{-}$) (a) and the activation energy obtained at a constant potential of $0.5 \mathrm{~V} v s$. RHE (blue line - -) (b) for EOR on bare and Bi-decorated THH Pd NCs as a function of Bicoverage. Activation energies were calculated from the Arrhenius plots using the current densities data from the CVs in the Fig. 5 at a constant potential of $0.5 \mathrm{~V} v s$. RHE.

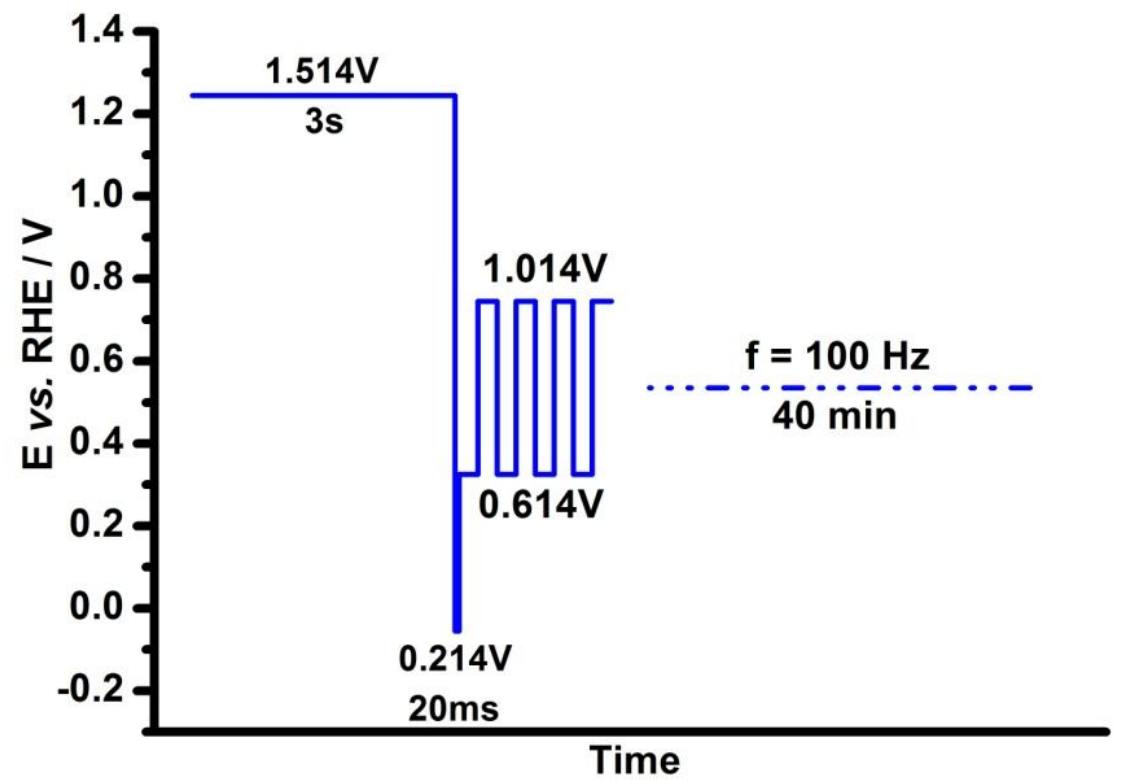

Fig.1

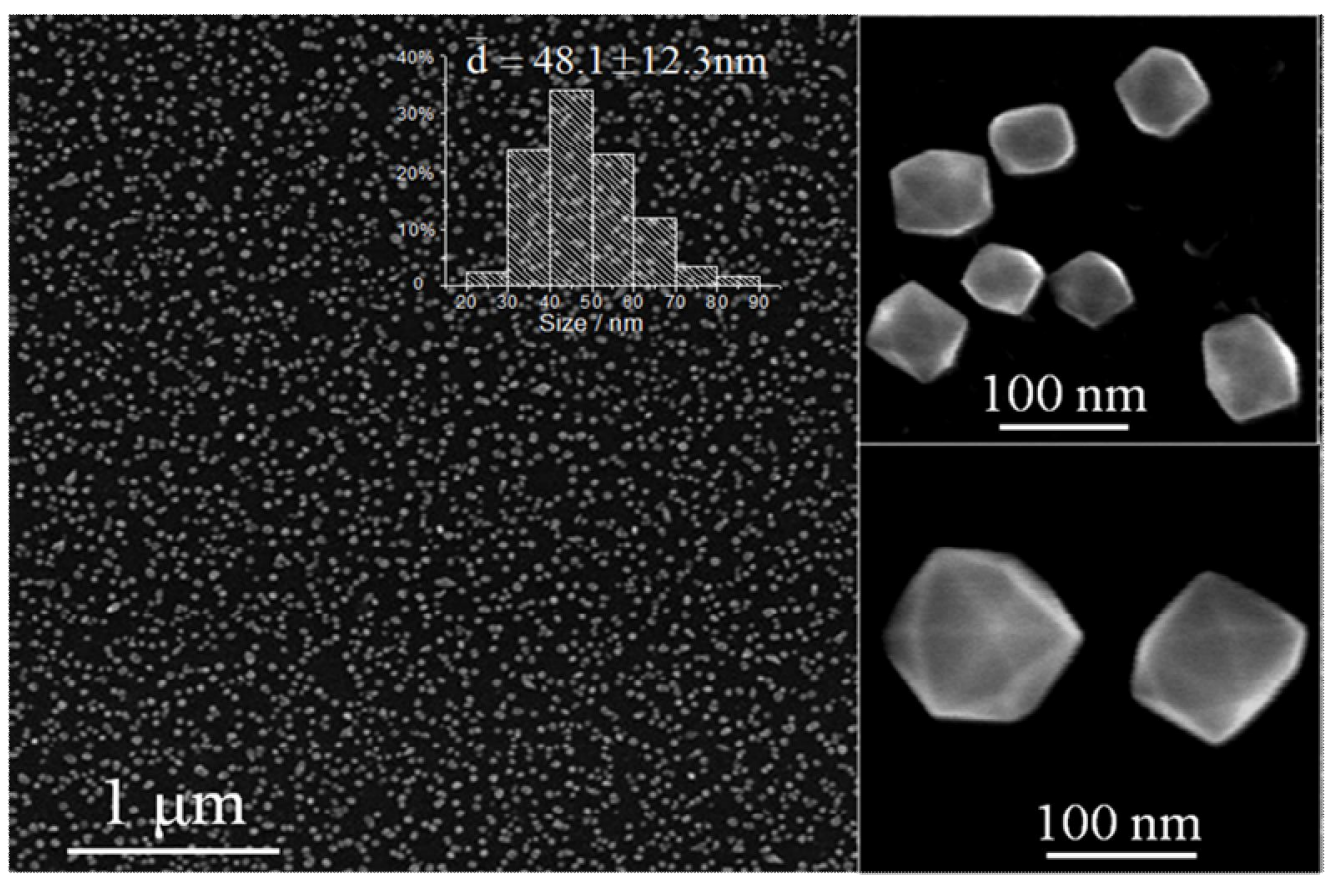

Fig. 2 
(a)

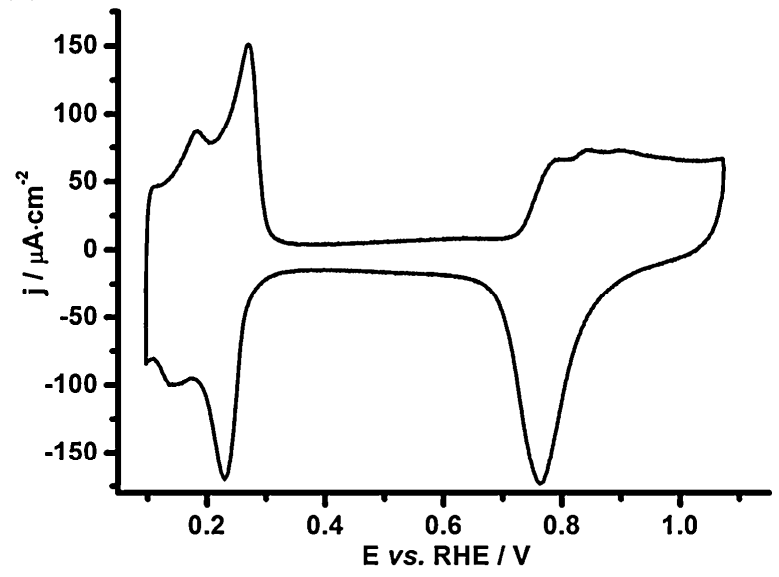

(c)

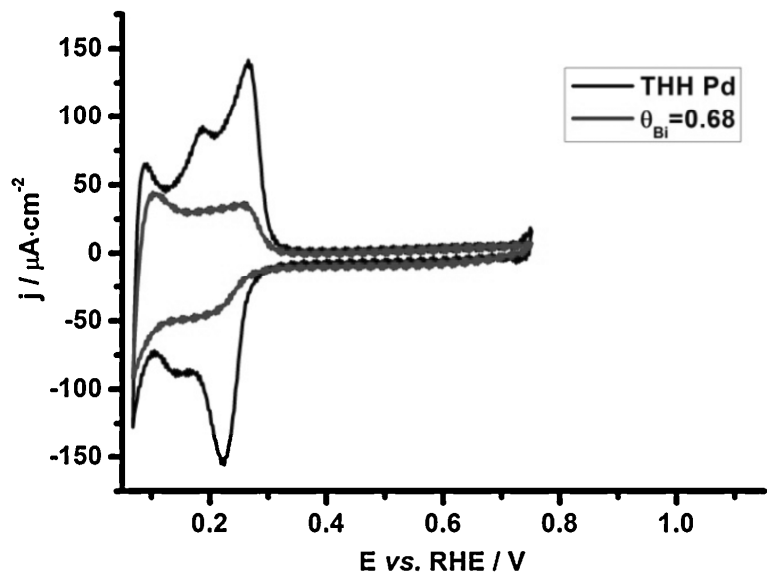

(e)

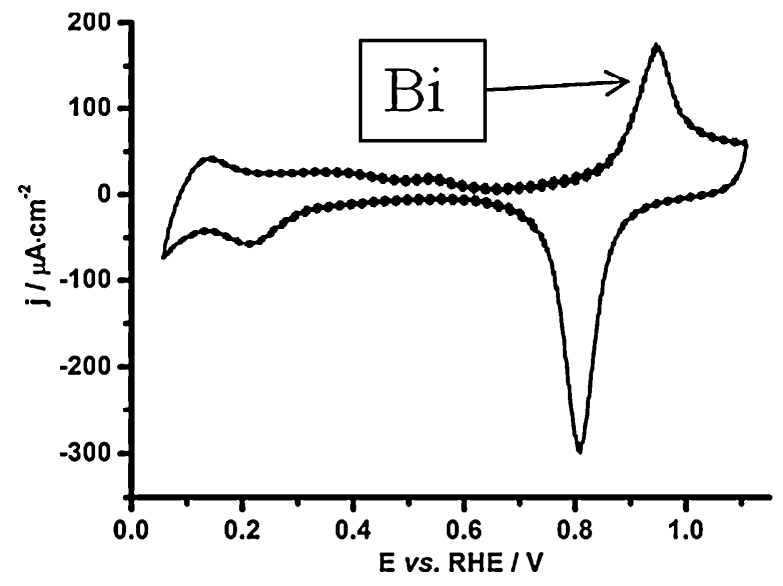

(b)

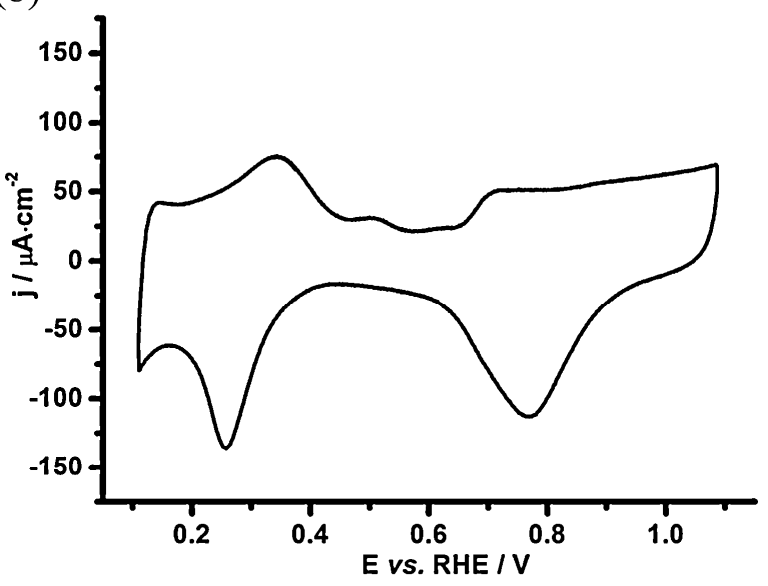

(d)

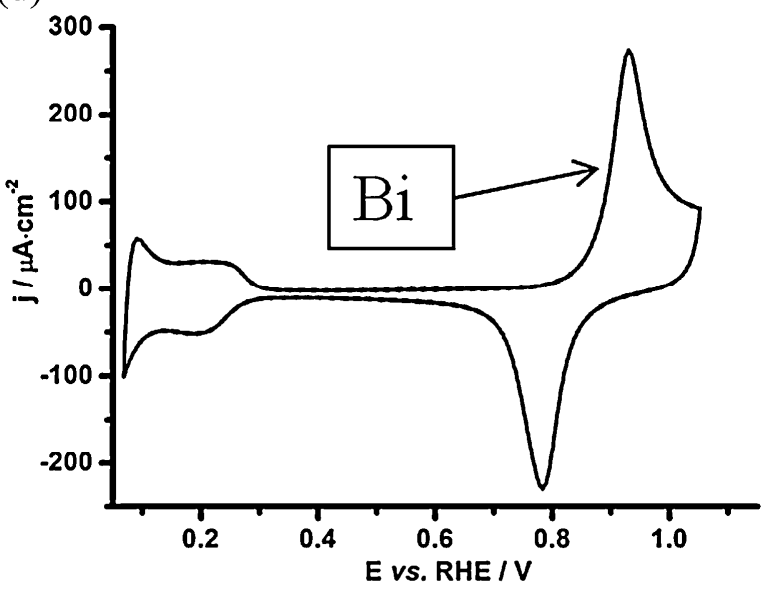

Fig. 3 

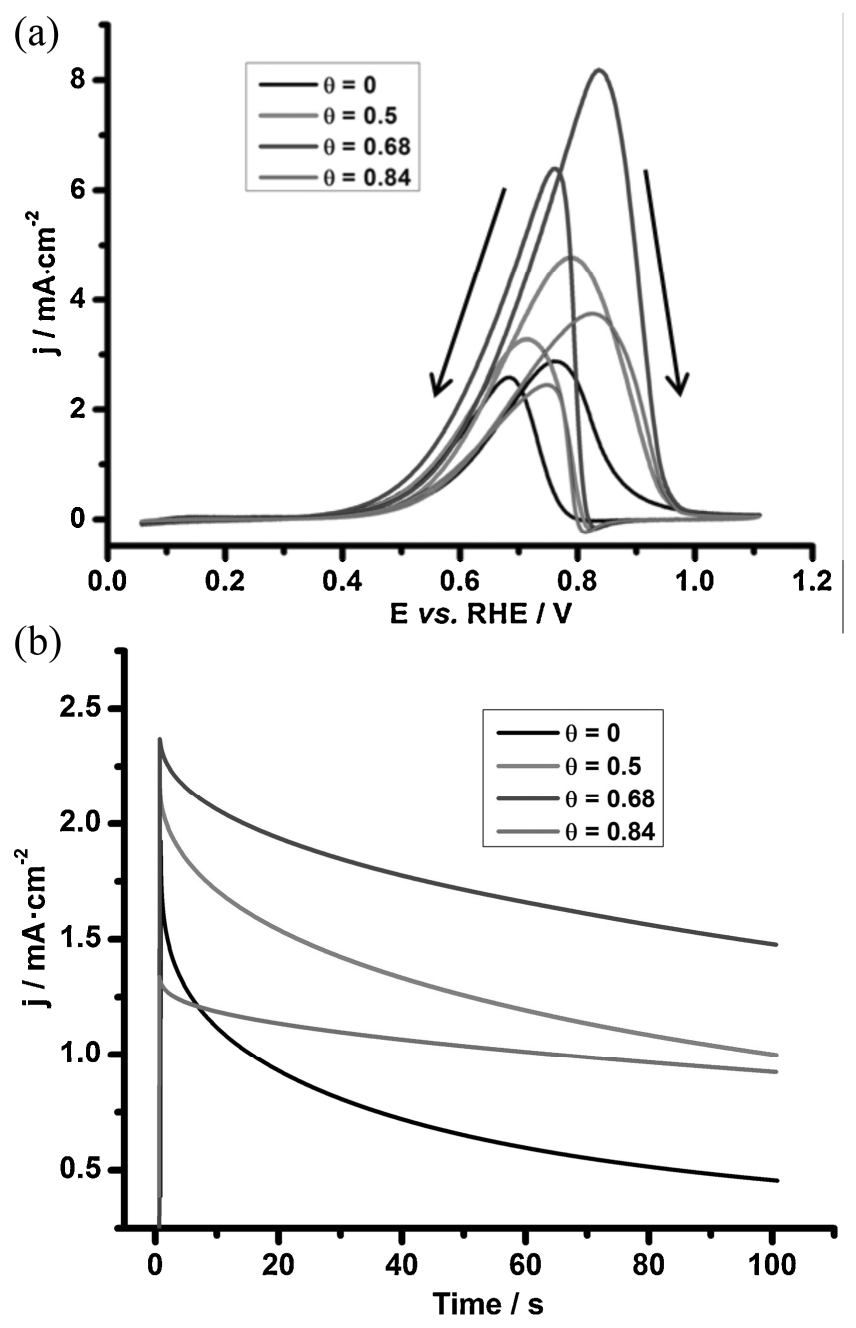

Fig. 4 
(a)

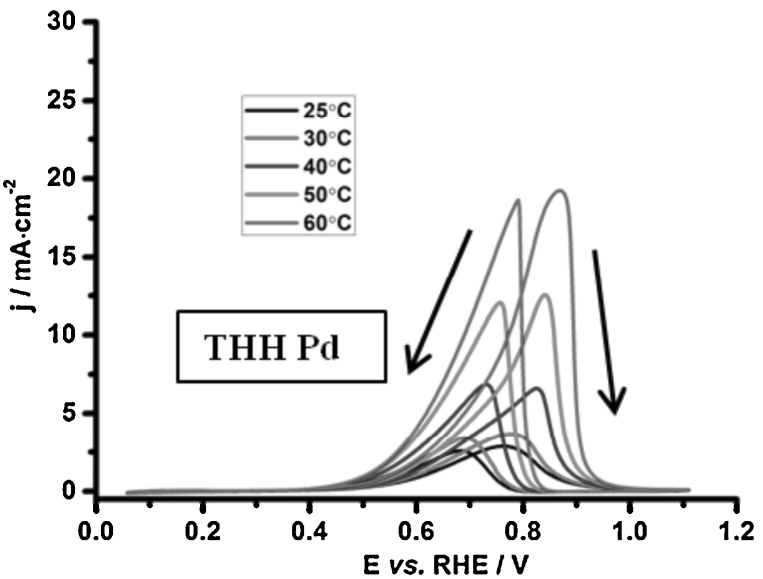

(c)

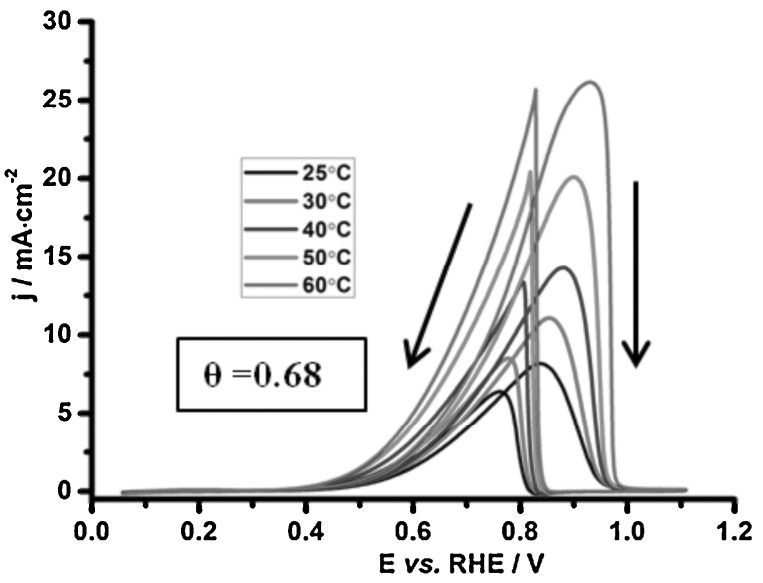

(e)

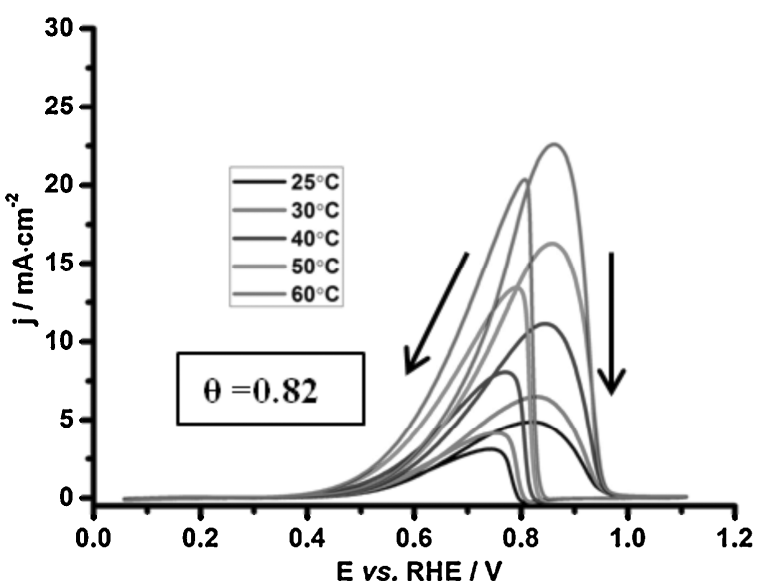

(b)

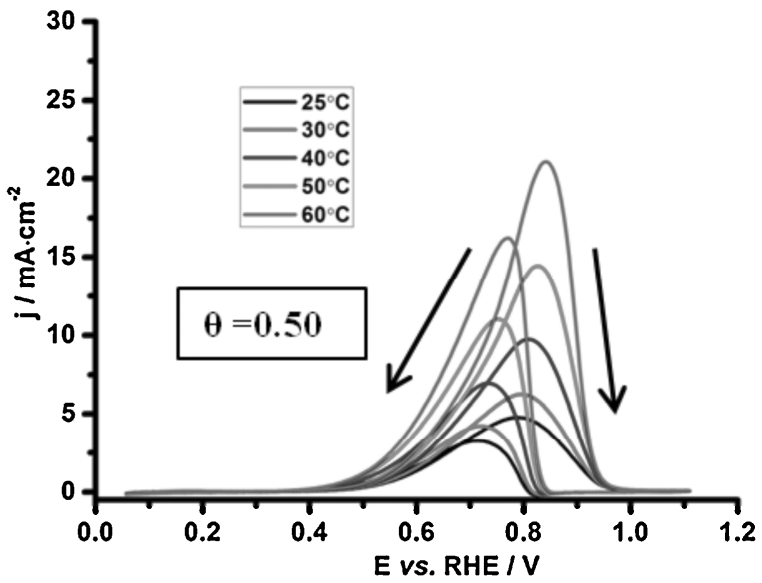

(d)

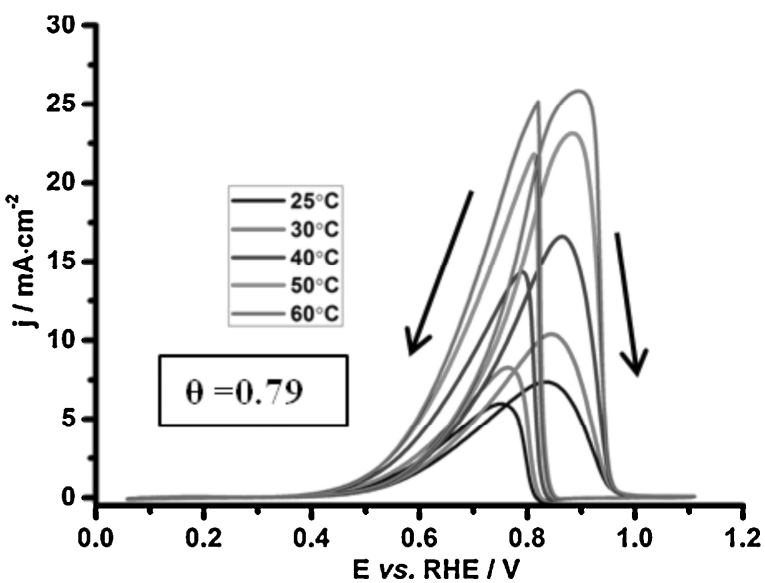

(f)

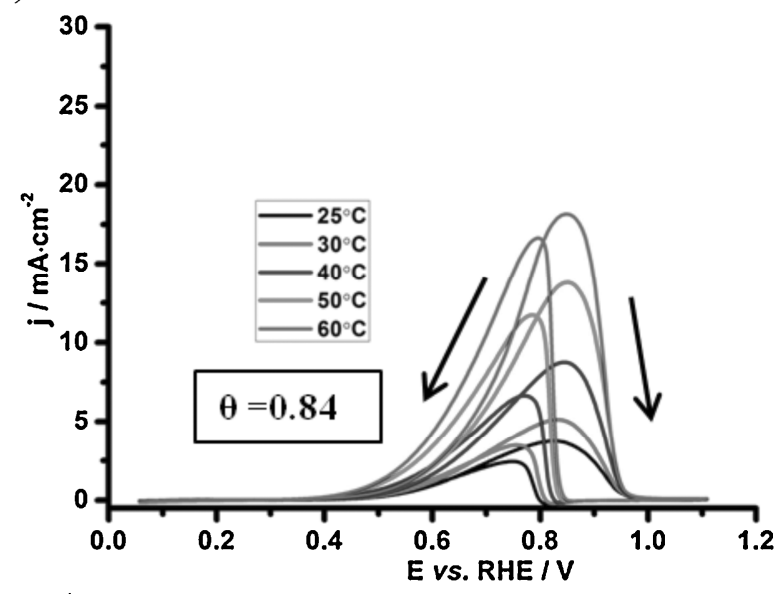

Fig.5 
(a)

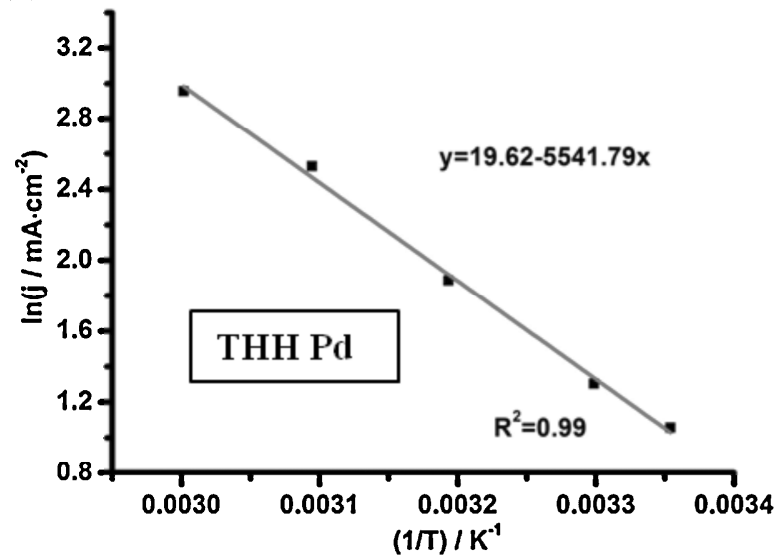

(c)

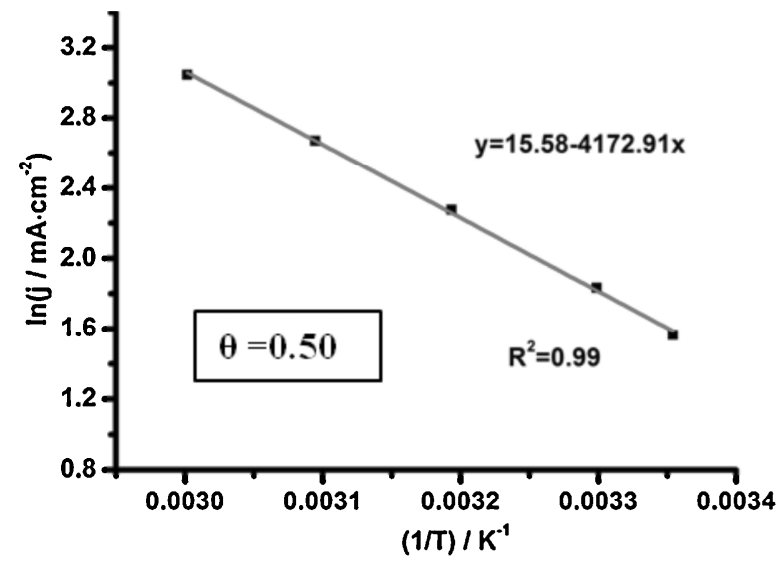

(e)

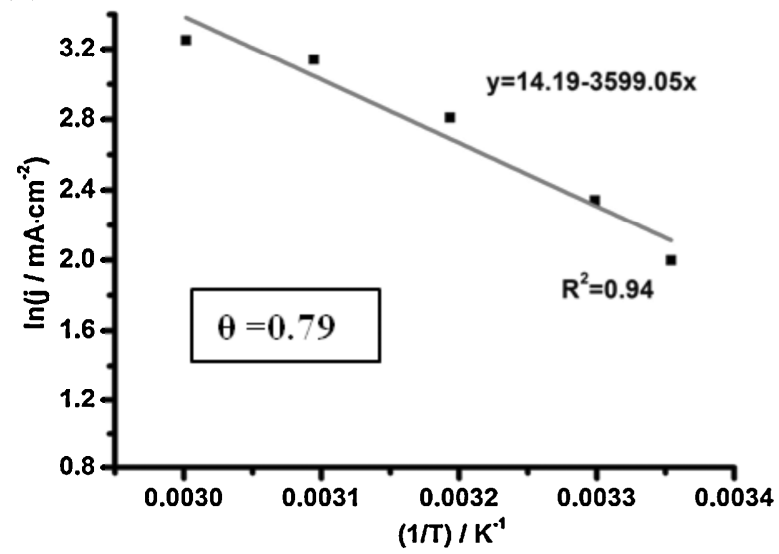

(b)

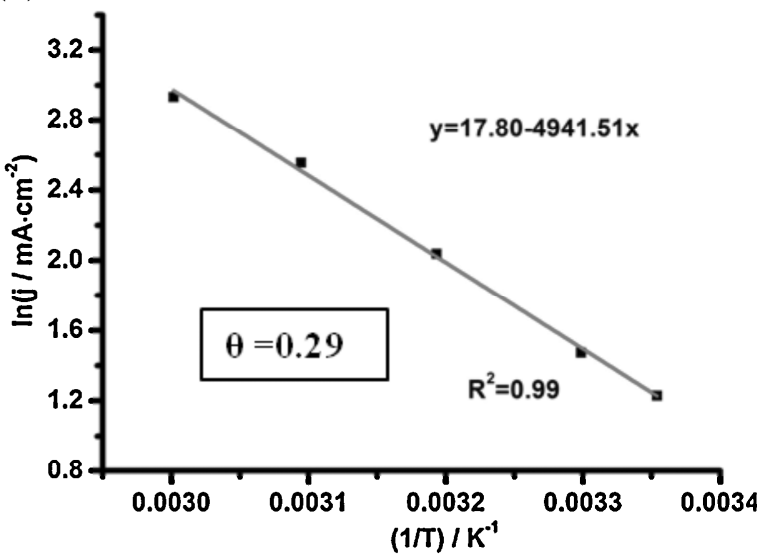

(d)

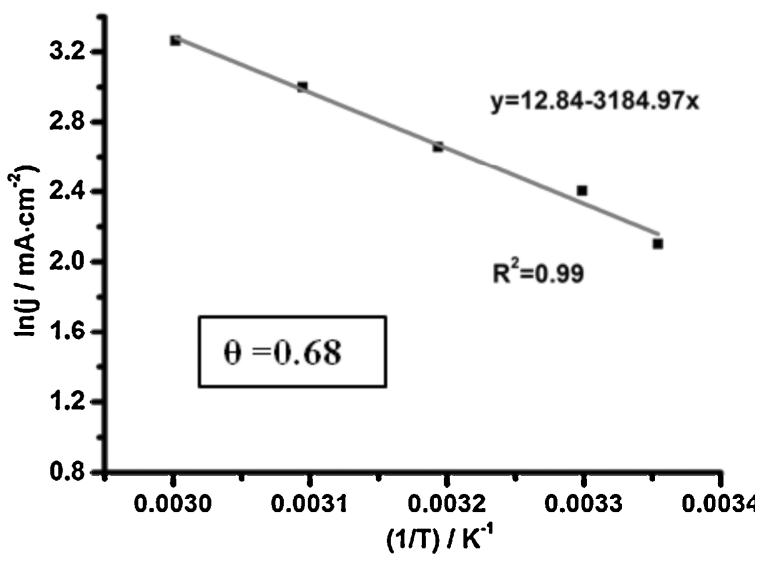

(f)

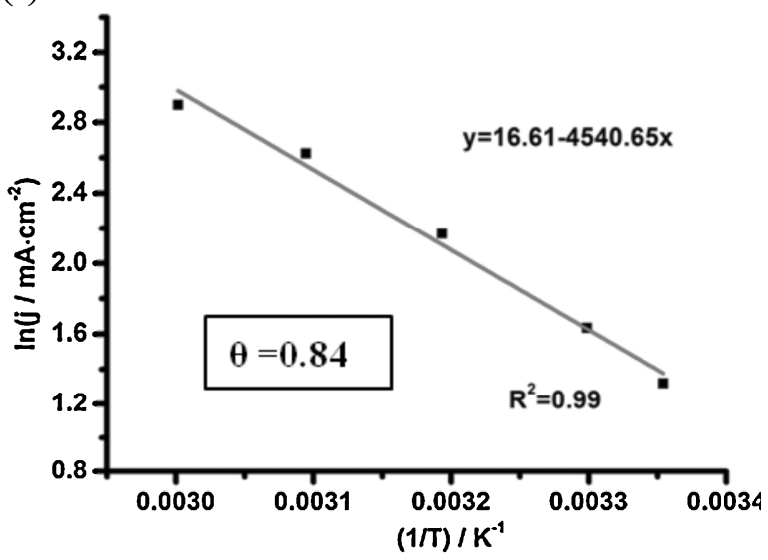

Fig. 6 


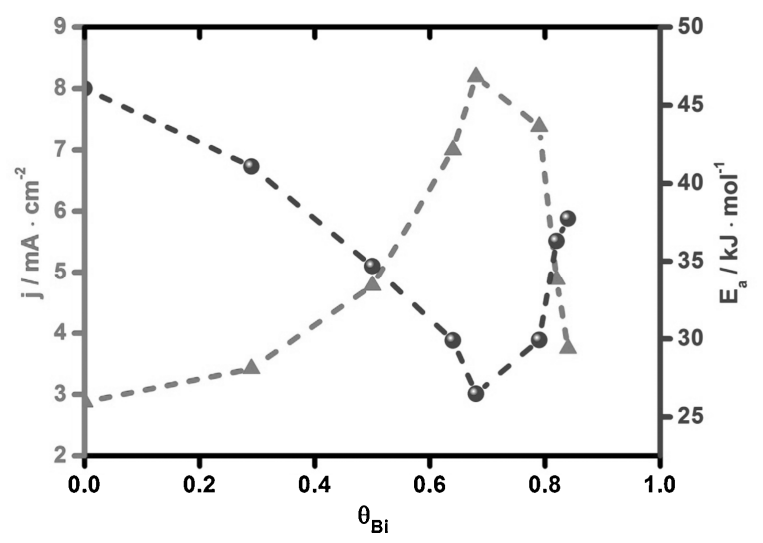

Fig. 7
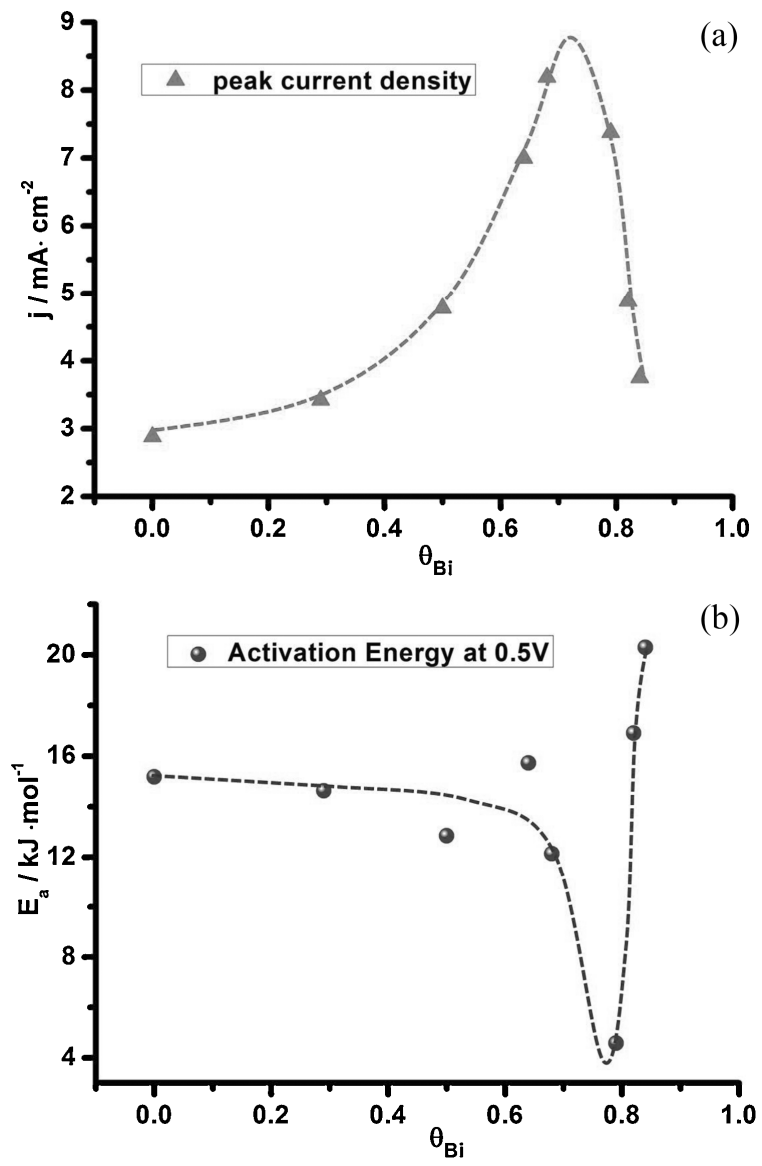

Fig. 8

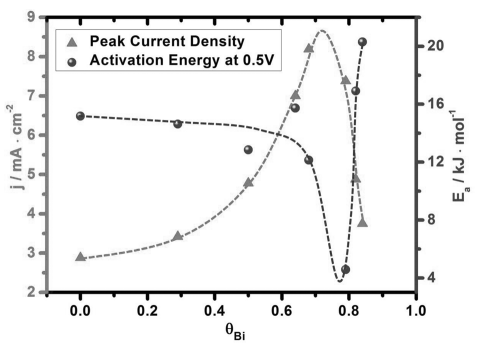

Graphical abstract 